Revue d'histoire de l'Amérique française

DEVVUE D'HISTOIRE DE L'AMÉRIQUE FRANÇAISE

\title{
Le Bulletin des recherches historiques et les sources imprimées de l'histoire du Canada français
}

\section{Jean-Pierre Chalifoux}

Volume 26, numéro 1, juin 1972

URI : https://id.erudit.org/iderudit/303154ar

DOI : https://doi.org/10.7202/303154ar

Aller au sommaire du numéro

Éditeur(s)

Institut d'histoire de l'Amérique française

ISSN

0035-2357 (imprimé)

1492-1383 (numérique)

Découvrir la revue

Citer cette note

Chalifoux, J.-P. (1972). Le Bulletin des recherches historiques et les sources imprimées de l'histoire du Canada français. Revue d'histoire de l'Amérique française, 26(1), 103-105. https://doi.org/10.7202/303154ar d'utilisation que vous pouvez consulter en ligne. 
NOTE DE RECHERCHE

\title{
LE BULLETIN DES RECHERCHES HISTORIQUES ET LES SOURCES IMPRIMÉES DE L'HISTOIRE DU CANADA FRANÇAIS
}

\author{
Jean-Pierre Chalifoux \\ Bibliothèque des sciences sociales \\ Université de Montréal
}

Dans le cadre d'une recherche documentaire poursuivie récemment, nous avons procédé à l'analyse du Bulletin des recherches historiques. L'examen des 726 numéros du Bulletin nous a permis de retracer un certain nombre de dépouillements de revues et de collections de documents. Nous en présentons ici le résultat sous forme de tableau.

Ces dépouillements ont été effectués par Pierre-Georges Roy et Antoine Roy. Les auteurs ont établi à partir des publications mentionnées, des listes de références bibliographiques afférentes à l'Histoire du Canada. Chaque dépouillement est présenté dans le BRH sous le titre général de "Sources imprimées de l'Histoire du Canada français", sauf les 3 titres précédés d'un + où la rubrique s'intitule: "A travers..." L'ensemble constitue une bibliographie de plus de 200 pages et regroupe plusieurs milliers de références. On y trouve la mention de nombreux articles d'intérêt biographique, de même que des sources intéressantes pour l'histoire politique, économique, culturelle et sociale du Québec. Les dates indiquées après le titre concernent la période couverte par le dépouillement. Nous souhaitons que la présentation de ce tableau puisse rendre service aux chercheurs.

RHAF, vol. 26, no 1 (juin 1972) 
Titre

\section{Abeille}

Annales

Annales térésiennes

Bulletin de la Société de Géographie de Québec

Bulletin de la Société de Géographie de Québec

+ Bulletin du parler français au Canada

Canada français

+ Canada français

Courrier du Livre

Echo du cabinet de lecture paroissiale de Montréal

Echo de la France

Gazette des familles canadiennes et acadiennes

Glaneur

Journal de l'Instruction publique

Kermesse

Margry, Pierre, Mémoires et documents pour servir à

l'histoire des origines françaises des pays d'outremer

Margry, Pierre, Mémoires et documents pour servir à

l'histoire des origines françaises...

Mémoires et comptes rendus - Société Royale du Canada

Monde illustré

Nouvelle France

Nouvelles soirées canadiennes

+ Nova Francia

Oiseau-mouche

Opinion publique

Opinion publique

Rapport des archives du Québec

Revue canadienne

Revue canadienne

Revue canadienne

Revue canadienne

Revue canadienne

Revue des Deux-Frances

Revue Nationale

Semaine Religieuse de Montréal

Semaine Religieuse de Montréal

Semaine Religieuse de Montréal

Semaine Religieuse de Montréal

Soirées canadiennes 
LES SOURCES IMPRIMÉES DE L'HISTOIRE DU CANADA FRANÇAIS

\begin{tabular}{|c|c|c|c|c|c|}
\hline Période & Volume & Numéro & Mois & Année & Pages \\
\hline$(1877-1882)$ & 34 & 10 & Oct. & 1928 & $607-615$ \\
\hline \multirow[t]{5}{*}{$(1922-1925)$} & 31 & 9 & Sept. & 1925 & $360-362$ \\
\hline & 38 & 1 & Janv. & 1932 & $84-88$ \\
\hline & 34 & 11 & Nov. & 1928 & 691-704 \\
\hline & 34 & 12 & Déc. & 1928 & $716-730$ \\
\hline & 37 & 5 & Mai & 1931 & 297-299 \\
\hline \multirow[t]{2}{*}{$(1888-1891)$} & 30 & 6 & Juin & 1924 & $186-190$ \\
\hline & 37 & 5 & Mai & 1931 & 292-297 \\
\hline (1899-1901) & 30 & 3 & Mai & 1924 & $84-87$ \\
\hline (1859-1873) & 28 & 2 & Févr. & 1922 & $45-49$ \\
\hline (1865-1869) & 29 & 3 & Mars & 1923 & $79-80$ \\
\hline (1869-1877) & 29 & 2 & Févr. & 1923 & $38-39$ \\
\hline (1890-1891) & 29 & 6 & Juin & 1923 & $177-178$ \\
\hline (1857-1879) & 28 & 1 & Janv. & 1922 & $20-23$ \\
\hline \multirow[t]{3}{*}{$(1892-1893)$} & 29 & 8 & Août & 1923 & $241-242$ \\
\hline & 35 & 8 & Août & 1929 & 503-512 \\
\hline & 35 & 9 & Sept. & 1929 & 554-575 \\
\hline (1882-1925) & 32 & 5 & Mai & 1926 & $301-312$ \\
\hline (1884-1908) & 31 & 8 & Août & 1925 & $305-320$ \\
\hline (1902-1918) & 30 & 4 & Avril & 1924 & $108-121$ \\
\hline \multirow[t]{2}{*}{$(1882-1888)$} & 29 & 4 & Avril & 1923 & $122-124$ \\
\hline & 37 & 4 & Avril & 1931 & $239-246$ \\
\hline (1893-1902) & 29 & 7 & Juill. & 1923 & $221-222$ \\
\hline$(1870-1883)$ & 31 & 10 & Oct. & 1925 & $402-412$ \\
\hline (1870-1883) & 31 & 11 & Nov. & 1925 & $493-506$ \\
\hline$(1920-1925)$ & 32 & 4 & Avr. & 1926 & $233-235$ \\
\hline (1864-1921) & 28 & 6 & Juin & 1922 & $171-177$ \\
\hline (1864-1921) & 28 & 7 & Juill. & 1922 & $210-216$ \\
\hline (1864-1921) & 28 & 10 & Oct. & 1922 & $314-320$ \\
\hline$(1864-1921)$ & 28 & 11 & Nov. & 1922 & $344-347$ \\
\hline \multirow[t]{7}{*}{$(1864-1921)$} & 28 & 12 & Déc. & 1922 & $360-363$ \\
\hline & 30 & 8 & Août & 1924 & 237. \\
\hline & 30 & 2 & Févr. & 1924 & $53-54$ \\
\hline & 35 & 1 & Janv. & 1929 & $55-64$ \\
\hline & 35 & 2 & Févr. & 1929 & $119-128$ \\
\hline & 35 & 3 & Mars & 1929 & $173-178$ \\
\hline & 35 & 4 & Avril & 1929 & $237-250$ \\
\hline$(1861-1865)$ & 28 & 3 & Mars & 1922 & $90-91$ \\
\hline
\end{tabular}

